\title{
Ensino direcionado às crianças disléxicas: entraves normativos e reflexões atuais
}

\author{
Teaching directed to dislexic children: normatives barriers and current reflections \\ Enseñanza dirigida a niños disléxicos: barreras normativas y reflexiones actuales
}

Recebido: 21/01/2021 | Revisado: 23/01/2021 | Aceito: 26/01/2021 | Publicado: 04/02/2021

\author{
Magno Alexon Bezerra Seabra \\ ORCID: https://orcid.org/0000-0002-2601-3155 \\ Universidade Federal da Paraíba, Brasil \\ E-mail: magnoalexon@hotmail.com \\ Anna Elizabeth de Carvalho Cavalcanti da Silveira \\ ORCID: https://orcid.org/0000-0002-2849-5696 \\ Universidade Federal da Paraíba, Brasil \\ E-mail: annaeccsilveira123@gmail.com \\ Girlene Gomes de Souza \\ ORCID: https://orcid.org/0000-0001-9292-0709 \\ Universidade Federal da Paraíba, Brasil \\ E-mail: girlenegomes30@hotmail.com
}

\begin{abstract}
Resumo
Objetivou-se com este estudo identificar elementos relativos aos aspectos didático-metodológicos utilizados pelo docente aos alunos disléxicos, envolvendo a formação inicial e continuada dos docentes, experiência no ensino, capacitação realizada na área de dislexia, recursos utilizados na aula e sugestões de atividades. A dislexia é considerada um Transtorno Específico de Aprendizagem, de acordo com a Associação Americana de Psiquiatria. Tratou-se de uma pesquisa de campo voltada para docentes do ensino fundamental de escolas públicas da cidade de João Pessoa, na Paraíba. Participaram, portanto, 78 docentes, os quais responderam às dez perguntas do questionário aplicado, via google forms. 90\% possuem cursos lato sensu, enquanto 10\% strictu sensu. $75 \%$ trabalham há mais de dez anos como professor, $15 \%$ entre um a cinco anos e $10 \%$ menos de um ano. $25 \%$ asseguraram que nunca estudou sobre dislexia, 55\% que o assunto foi pouco explorado, $15 \%$ acreditam que estudou de maneira regular, e, por fim, 5\% julgam que a temática foi explorada significativamente. $23 \%$ responderam que não se sentem capazes de lidarem com disléxicos, $28 \%$ afirmaram que sim e $49 \%$ assinalaram que talvez. $65 \%$ afirmaram que já fizeram uso de atividades variadas, para aplicar aos sujeitos com dislexia e 35\% asseguraram que não. Assim como ocorre em outras profissões, o docente precisa se capacitar constantemente, para lidar com os obstáculos encontrados na sua jornada de trabalho, pois lecionar exige preparo, motivação e formação adequada. Logo, lidar com crianças disléxicas exige uma formação inicial ou continuada direcionada para esses sujeitos.
\end{abstract}

Palavras-chave: Dislexia; Formação docente; Ensino.

\begin{abstract}
The objective of this study was to identify elements relatives to the didactic-methodological aspects used by the teacher to dyslexic students, involving the initial and continuing training of teachers, teaching experience, training carried out in the area of dyslexia, resources used in the classroom and suggestions for activities. Dyslexia is considered a Specific Learning Disorder, according to the American Psychiatric Association. It was a field research aimed at elementary school teachers in public schools in the city of João Pessoa, Paraíba. Therefore, 78 teachers participated, answered the ten questions of the applied questionnaire, through google forms. $90 \%$ have lato sensu courses, while $10 \%$ strictu sensu. $75 \%$ work for more than ten years as teacher, $15 \%$ between one and five years and $10 \%$ less than a year. 25\% assured that they had never studied dyslexia, 55\% that the subject was little explored, $15 \%$ believed that they studied regularly, and, finally, $5 \%$ believed that the topic was explored significantly. $23 \%$ answered that they do not feel capable of dealing with dyslexics, $28 \%$ stated that yes and $49 \%$ said that maybe. $65 \%$ said already used various activities to apply to subjects with dyslexia and 35\% said did not. As in other professions, teachers need to be constantly trained to deal with the obstacles encountered in their workday, as teaching requires preparation, motivation and adequate training. Therefore, dealing with dyslexic children requires initial or continuous training directed to these subjects.
\end{abstract}

Keywords: Dyslexia; Teacher training; Teaching.

\section{Resumen}

El objetivo de este estudio fue identificar elementos relacionados con los aspectos didáctico-metodológicos utilizados por el docente a los estudiantes disléxicos, involucrando la formación inicial y continua de los docentes, la experiencia docente, la formación realizada en el área de la dislexia, los recursos utilizados en el aula. y sugerencias de 
actividades. La dislexia se considera un trastorno específico del aprendizaje, según la Asociación Estadounidense de Psiquiatría. Se trató de una investigación de campo dirigida a profesores de primaria en escuelas públicas de la ciudad de João Pessoa, Paraíba. Por lo tanto, participaron 78 docentes, respondieron las diez preguntas del cuestionario aplicado, a través de formularios de google. El $90 \%$ tiene cursos latu sensu, mientras que el $10 \%$ Strictu sensu. El $75 \%$ trabaja más de diez años como docente, el $15 \%$ entre uno y cinco años y el $10 \%$ menos de un año. E1 $25 \%$ aseguró que nunca había estudiado la dislexia, el 55\% que el tema fue poco explorado, el 15\% creía que estudiaba regularmente y, finalmente, el 5\% creía que el tema se exploró de manera significativa. El 23\% respondió que no se siente capaz de lidiar con disléxicos, el $28 \%$ dijo que sí y el $49 \%$ dijo que tal vez. El $65 \%$ dijo que ya utilizaba diversas actividades para aplicar a sujetos con dislexia y el 35\% dijo que no. Como en otras profesiones, los docentes necesitan una formación constante para afrontar los obstáculos que encuentran en su jornada laboral, ya que la docencia requiere preparación, motivación y una formación adecuada. Por lo tanto, tratar con niños disléxicos requiere una formación inicial o continua dirigida a estos asignaturas.

Palabras clave: Dislexia; Formación de professores; Enseñando.

\section{Introdução}

Muitos professores encontram dificuldades, em lidar na sala de aula, com a diversidade de alunos com singularidades específicas. Essa realidade causa apreensão, devido a proposta de incluir pessoas com diferentes características, pois o foco não se encontra, primordialmente, na absorção do conteúdo, contudo no desenvolvimento interpessoal e social do sujeito.

Antes, a escola rejeitava sumariamente às pessoas que tinham dificuldades de adaptação escolar; todavia, nos tempos hodiernos, a realidade é bastante diferenciada, uma vez que os profissionais da educação buscam estar atentos a grande demanda de alunos com particularidades específicas.

A inclusão é um tema debatido desde dos fins da década de 1980, adentrando-se nos anos posteriores, e ainda é uma temática passível de muita discussão, pois envolve questões conceituais e de aplicabilidade social.

Incluir as diferentes crianças na escola tem sido um grande desafio aos professores, pois enfrentam questões relativas à área orgânica do sujeito, e isso não é fácil de se resolver, tendo em vista que aprender envolve uma série de fatores: afetivos, cognitivos e motores. E quando se refere a natureza de outras necessidades dos alunos, os professores precisam possuir conhecimentos sobre. Logo, além de identificar o contexto social dos estudantes, os docentes precisarão saber sobre as diferentes síndromes, transtornos ou distúrbios, tendo em vista proporcionar uma formação escolar, desenvolvimento humano e aprendizagens adequadas.

Nesse sentido, a dislexia trata-se de um distúrbio de aprendizagem com base neurobiológica, que afeta sujeitos, independente de classe social, idade, escolaridade, sexo, origem familiar, dentre outros fatores. Por essa razão, compreendê-la é uma necessidade de todo professor que tem aluno disléxico em sala de aula. Diante disso, este estudo teve como objetivo identificar elementos relativos aos aspectos didático-metodológicos utilizados pelo docente aos alunos disléxicos, envolvendo a formação inicial e continuada dos docentes, experiência no ensino, capacitação realizada na área de dislexia, recursos utilizados na aula e sugestões de atividades.

\section{Metodologia}

Aplicou-se um questionário com dez perguntas aos pesquisados, através do google forms. Responderam ao instrumento setenta e oito professores do ensino fundamental de escolas públicas, localizadas no município de João Pessoa/Paraíba. Tratou-se de uma pesquisa quantitativa e qualitativa, tendo em vista que se utilizou de porcentagens como referência para análise, e posteriormente inferir sobre os resultados (Pereira, Shitsuka, Parreira, \& Shitsuka, 2018).

Inclusive, constatou-se complementaridade no uso do método misto, permitindo convergências na triangulação: resultados desta pesquisa, teoria/pesquisa sobre a temática e conhecimento das práticas nas instituições escolares da cidade. Nesse sentido, na visão de Santos et. al. (2017), "Há uma integração quando os bancos de dados qualitativos e quantitativos 
estão fundidos e produzem informações que se apoiam mutuamente.” Essa colocação corrobora com o se identificou neste estudo.

\section{Resultados e Discussões}

Quanto à formação dos sujeitos, 90\% possuem pós-graduação (lato sensu) e $10 \%$ strictu sensu a nível de mestrado, com predominância na área da educação. Com relação ao tempo que trabalham no ensino fundamental, atuando como professor, $75 \%$ trabalham faz mais de dez anos, $15 \%$ entre um a cinco anos e $10 \%$ menos de um ano. Com relação ao ano/série que a docente ensina atualmente, $15 \%$ ensinam no primeiro ano, $18 \%$ no segundo, $20 \%$ no terceiro, $19 \%$ no quarto e $28 \%$ no quinto ano.

Acredita-se que o fato de os professores estudarem sobre a temática durante a sua vida acadêmica, ou mesmo através de cursos avulsos, contribui para atuação no âmbito profissional. Diante disso, 25\% alegaram que nunca estudou sobre dislexia, 55\% que o assunto foi pouco explorado, 15\% acreditam que estudou de maneira regular, e, por fim, 5\% julgam que a temática foi explorada significativamente. Tais dados revelam que o estudo da dislexia, nos cursos de formação inicial e continuada ainda carecem de maior atenção, tendo em vista a necessidade de se trabalhar com esses sujeitos, uma vez que a realidade atual é configurada com pessoas disléxicas. Inclusive, esse tema é defendido por Carreira (2016) quando registra a importância de uma adequada formação para atuar no dia a dia nas especificidades de cada estudante. E acrescenta que: “A escola deve interessar pela preparação contínua dos seus profissionais, principalmente do professor, para que o mesmo tenha boas condições de trabalhar com alunos que tenham dificuldades no aprendizado, especialmente o distúrbio da dislexia." (Carreira, 2016, p. 32).

Além da formação inicial de cada profissional, é fundamental que o ambiente de trabalho, no caso, a escola, ofereça cursos de capacitação a partir da clientela absorvida. Sobre esse aspecto, não é comum que organizações (escolas) se voltem para um plano de qualificação docente ou mesmo dos demais profissionais.

Ao perguntar se os docentes se consideram capazes de identificar um estudante disléxico, 23\% responderam que não, $28 \%$ afirmaram que sim e $49 \%$ assinalaram que talvez. Conforme respostas, é notório que menos de $1 / 4$ se sentem capazes de detectar, ao contrário de $2 / 3$ que se não se consideram apto, pois ao responderem talvez não demonstraram segurança na questão. Assim, evidencia-se a necessidade de preparação para ao menos identificarem alunos com dislexia. Recorda-se que $75 \%$ por docentes trabalham na área há mais de dez anos, então, percebe-se que a experiência como professor não é requisito para confirmar a dislexia.

Para Lima citado por Assunção (2018), a instituição escolar precisa estar atenta as necessidades dos alunos, especialmente àqueles com problemas de aprendizagem. Portanto, não basta apenas ensinar, é preciso planejar, inovar, mapear o perfil dos estudantes para que a escola de fato, não seja mera transmissora de conteúdos, mas uma organização que transforme sujeitos a partir da particularidade de cada um, pois não é novidade que o docente exerce um papel fundamental na sala de aula, inclusive que marca o aluno para toda uma vida. Citando como exemplo, a atuação de um profissional de saúde no sujeito é logo percebida pelo paciente, pois haverá melhora ou não; mas a ação de um professor, é percebida com o tempo, porque este lida com formação e esta é construída com contínuas ações e reflexões que irão contribuir ou não positivamente, para o desenvolvimento do indivíduo.

Com relação a experiência com estudantes disléxicos, $20 \%$ dos professores asseguraram que nunca tiveram alunos com dislexia, $15 \%$ afirmaram que talvez e $65 \%$ registraram que sim. O que se percebe é que mesmo com contato com discentes com dificuldades na leitura, os professores em geral, não tem procurado compreender sobre o transtorno. Logo, é importante o registro de dois questões cruciais, uma com relação a ignorância quanto ao transtorno, e a segunda, é que mesmo não sabendo sobre ou pouco conhecendo, os docentes não providenciaram estudar especialmente a dislexia. 
O Manual de Diagnóstico Estatístico de Transtornos Mentais - DSM-V (American Psychiatric Association [APA], 2014), categoriza a dislexia como Transtorno Específico de Aprendizagem, e registra como critérios diagnósticos os seguintes pontos:

1. Leitura de palavras de forma imprecisa ou lenta e com esforço (p. ex., lê palavras isoladas em voz alta, de forma incorreta ou lenta e hesitante, frequentemente adivinha palavras, tem dificuldade de soletrá-las).

2. Dificuldade para compreender o sentido do que é lido (p. ex., pode ler o texto com precisão, mas não compreende a sequência, as relações, as inferências ou os sentidos mais profundos do que é lido). (APA, 2014, p. 66)

Conforme se verifica acima, a dislexia é caracterizada pela dificuldade na leitura, seja pela ausência de clareza, lentidão ou mesmo ao codificar as letras. Além de possuir discrepância na interpretação das palavras ou mesmo nas frases.

Essas inconsistências na leitura, ainda segundo o DSM-V (2014), precisam persistir num período de, no mínimo, seis meses, considerando que o sujeito foi acompanhado por profissionais para superar as limitações relacionadas à dislexia.

Segundo Maradei, Maia e Seabra (2020), a identificação da dislexia pode ocorrer em diferentes fases da aprendizagem, contextos, nacionalidades; contudo, é comum ser constatada nos primeiros anos escolares, principalmente se o sujeito de perfil grave, tendo em vista que é mais facilmente identificada, pois, muitas vezes, além de possuir desarmonia no ato de ler, também possui limitações na interação com seus colegas de sala e demais pessoas.

Ao questionar se o disléxico possui inteligência abaixo da média, 9\% afirmaram que sim e 91\% asseguraram que não. Tais respostas são provenientes das experiências dos participantes, com pessoas disléxicas. Nesse âmbito, Rubino (2008) comenta que:

Os disléxicos têm inteligência acima da média, apesar de seu desempenho escolar sugerir o contrário. As pessoas disléxicas mostram-se mais criativas e têm ideias inovadoras que superam as das pessoas não-disléxicas, uma vez que elas tendem a ativar outras áreas do cérebro para compensar as suas dificuldades. Personalidades célebres como Albert Einstein, Thomas Edison, Walt Disney e Agatha Christie eram disléxicas (Rubino, 2008, p. 85)

Baseado na visão da autora acima, os disléxicos além de possuírem inteligência acima da média são mais criativos, e cita cientista, inovadores e a escritora Agatha Christie, para respaldar seu registro. Corroborando essa questão, o DSM-5 registra que a dislexia compromete a aprendizagem do sujeito, contudo demonstram níveis comuns aos demais indivíduos quanto ao funcionamento intelectual.

De acordo com a Teoria das Inteligências Múltiplas, Gardner (1994) segmenta a inteligência da seguinte forma: interpessoal, intrapessoal, lógico-matemática, espacial, corporal-cenestésica, verbal-linguística, musical, naturalista, existencial e pictórica. O disléxico tem um maior comprometimento na espacial, corporal-cenestésica, verbal-linguística e pictórica. No entanto, não invalida com que não possa aprender, pois mesmo com dificuldades existentes, há a possibilidade de sobressair e superar suas limitações através da dedicação e estratégias, principalmente por profissionais capacitados da educação. Inclusive, a forma como cada sujeito aprende, é diferente; portanto também necessita de diferentes maneiras de aprender. Assim, não coaduna com a pedagogia tradicional, uma vez que esta trabalha com um ensino uniforme aos indivíduos que estão matriculados numa mesma sala de aula. Logo, a importância de planejar estratégias para cada aluno é bastante pertinente, pois facilitará para todos e a educação atingirá o seu objetivo, que é a formação e aprendizagem dos seus discentes. Com relação a questão de aprender, Ramos, Seabra e Toledo (2018, p. 31) registram:

Para falar em aprendizagem, é necessário entender a complexidade e a amplitude que o tema abrange. Considera-se como um processo de mudança de comportamento observável ou não, que acontece quando alguém tem uma experiência construída através de causas cognitivas, neurológicas e relacionais. A complexidade maior está na constatação de como se aprende. (Ramos, Seabra, \& Toledo, 2018, p. 31). 
Logo, falar sobre aprendizagem é simples, no entanto, realizar em como o sujeito aprende exige muito mais que teorizar, requer prática e reflexões continuamente, tanto no sentido do ensino aos disléxicos, quanto à aprendizagem de um único sujeito, pois esse está em constante transformação, seja orgânica, social, psicológica, dentre outros fatores.

Inclusive, mesmo que existam mais de um disléxico numa mesma sala de aula, não significa dizer que o planejamento seja o mesmo, pois as dificuldades de cada aluno, é possível que seja diferenciada em relação ao outro, pois além de pontos específicos de limitação, há o nível de comprometimento. Dessa forma, inicialmente, o planejamento deve ocorrer a partir do levantamento do perfil de cada sujeito, para que se possa, de fato, atingir à finalidade almejada.

Ao indagar o/a docente sobre quais dificuldades são identificadas nos alunos que ele/a associa à dislexia. 22\% relacionam a dislexia à escrita, outros $22 \%$ à ortografia, $22 \%$ à compreensão textual, nenhum docente associou aos cálculos matemáticos, $34 \%$ relacionaram às dificuldades de leitura e escrita, mas nenhum/a docente associou exclusivamente às limitações da leitura. De acordo com os resultados, os sujeitos da pesquisa relacionaram a dislexia à língua portuguesa, pois nenhum selecionou a relação entre dislexia e a matemática.

Segundo o DSM-5 (APA, 2014), o transtorno específico de aprendizagem detalha as limitações quanto à leitura, à escrita, à ortografia e a matemática. Tais especificações, sinaliza para as seguintes compreensões: dislexia -> limitações na leitura, disgrafia $\rightarrow$ limitações na grafia/forma das palavras, disortografia $\rightarrow$ limitações na ortografia/escrita das palavras, discalculia -> limitações em matemática.

Ao serem questionados sobre a utilização de metodologia diferenciada para atuar com alunos disléxicos, 65\% afirmaram que já fizeram uso de atividades variadas e 35\% asseguraram que não. Esses percentuais são semelhantes, quando os docentes também responderam que ministraram a crianças com dislexia (65\%). De fato, trabalhar com crianças disléxicas é um desafio ao professor, pois precisa elaborar atividades específicas. Maradei, Maia e Seabra (2020), em sua publicação, propõem atividades direcionadas a crianças disléxicas, como é o caso do jogo da forca temático, caça palavras e produção de placas com identificação de sentimentos.

Também se perguntou, qual a maior barreira enfrentada com alunos com dificuldades de leitura. 55\% assinalaram que é falta de apoio dos pais aos discentes, $15 \%$ a baixa auto estima dos alunos, $10 \%$ consideram que a falta de capacitação por parte dos profissionais da educação, $12 \%$ asseguraram que a falta de recursos de apoio (material didático) e $8 \%$ sinalizaram a falta de auxílio para realizar atividades individualizadas.

A partir dos dados constatados, a ausência dos familiares ao apoio às crianças, para os docentes, é a mais preocupante. Diante disso, compreende-se tal preocupação, uma vez que quando o sujeito tem uma base, ou pessoas que aceitam e estão prontos para ajudar, a criança se desenvolve com mais segurança e eficácia. Nenhum dos fatores acima sinalizado, pelos docentes, pode deixar de ser desconsiderado, uma vez que todos são necessários para o êxito formativo do indivíduo. Portanto, sempre que a escola puder contar com a família na educação da criança, se torna bastante eficiente, pois o que a escola executa, quando é endossado pela família, o êxito alcançado é mais rápido e sólido.

Nesse aspecto, Seabra registra (2013, p. 243):

Existem alguns entraves que obstacularizam o sucesso da relação entre criança, família e escola. Quando há o primeiro deles é a não aceitação da família sobre alguns aspectos de ordem orgânica da criança. No momento em que a família aceita a condição da criança, ela avança para o próximo estágio, tão grave quanto o primeiro, caso não seja superado, é o fato de a família não identificar qual o caminho que deve trilhar para a superação das limitações da criança. É possível que nesse segundo momento, a família vivencie essa etapa de dúvidas e incertezas por um maior período. Caso a mãe consiga encontrar a trajetória, que conduzirá a criança, poderá contribuir para o seu desenvolvimento, uma vez que irá buscar estratégias para o crescimento do seu filho, para a professora será o seu aluno. Os pais enquanto referência na vida da criança, contribuirão, sobremaneira, na aprendizagem. (Seabra, 2013, p. 243) 
De acordo com o autor acima citado, a família exerce papel fundamental na educação da criança, e que o primeiro obstáculo é a não aceitação da condição de seu filho. Isso posto, dificultará na formação do sujeito, pois, a partir do momento em que os pais ou responsáveis aceitam e compreendem a condição dos seus filhos, o próximo passo seria buscar ajuda de profissionais capacitados. Esse tipo de postura é um ganho significativo para todos, ou seja, escola, família, e principalmente as próprias crianças. Apesar de que, infelizmente, concordando com Seabra e Santiago (2020, p. 20): “É mais fácil discriminar, segregar, marginalizar e excluir, que compreender, aceitar e incluir”. Pois, exige dedicação, visão, construção, enquanto separar apenas, requer a própria ignorância.

Com relação ao aspecto da autoestima do disléxico, é importante que o docente busque conquistar a autoconfiança, identificando as habilidades encontradas e mostrando ao discente, pois o professor, além de ministrar conteúdos, educar as crianças, precisa ter sensibilidade para atuar, tendo em vista que lida com sujeitos, muitas vezes vulneráveis e carentes de confiança e atenção.

De acordo com Seabra, Almeida e Félix (2016, p. 215):

Outra abordagem útil é a de ensinar as crianças competências que permitirão se desenrolar com desenvoltura em situações que até então eram fonte de frustração ou de estresse. Podendo sempre levar em consideração o ambiente ao qual está inserido esse indivíduo, com a finalidade de poder dar ao mesmo, valiosos meios de enfrentar ou evitar situações de dificuldades que venham a ocorrer nesse ambiente [...] (Seabra, Almeida, \& Félix, 2016, p. 215).

Essa questão, levantada pelos autores acima, desemboca no comportamento dos disléxicos, pois há aqueles que não tem postura diferenciada dos demais, porém há outros que podem ser identificados por possuírem algum distúrbio. Por isso, é sugerido que os docentes necessitem planejar atividades que promovam o desenvolvimento do sujeito, para superar limitações que privam a fala, a ação e a interação com os colegas, professores e familiares.

\section{Conclusão}

Do mesmo modo que ocorre em outras profissões, o docente precisa se capacitar constantemente, para lidar com os obstáculos encontrados na sua jornada de trabalho, pois lecionar exige preparo, motivação e formação adequada. O professor lida com aspectos burocráticos, relativos à instituição escolar e com o desenvolvimento dos sujeitos sob sua responsabilidade, e para que isso ocorra é fundamental que estude diferentes metodologias para atender aos diversos públicos e assim atenda ao objetivo educativo.

Este estudo teve como finalidade verificar os elementos relativos aos âmbitos didático-metodológicos usados pelos professores de estudantes disléxicos. Assim, identificou-se que poucos professores estudaram sobre a dislexia no período em que realizou seu curso que habilitou como docente, e mesmo àqueles que estudaram o tema, foi de forma incipiente. Mais de $50 \%$ foram professores de alunos disléxicos, o que contrapõem as dificuldades citadas no decorrer deste estudo, no sentido de continuar tendo dificuldades em lidar com tais sujeitos. É como se a experiência com crianças com dislexia, ainda não fosse suficiente para enfrentar uma nova demanda com os mesmos sujeitos. Por um lado, é compreensivo, uma vez que cada vivência é específica e particular, mas, por outro, quer queira ou não, o fato de ter sido professor de aluno disléxico facilita compreender outros alunos com dislexia, mesmo apesar das diferenças de personalidade, de níveis e de aspectos mais específicos da dislexia. E mais, é um desafio para os docentes lidarem com estudantes com dificuldades de aprendizagem, especialmente quando essas estão associadas a causas orgânicas.

Como sugestão, é interessante que novas pesquisas se realizem, tendo como temática a dislexia, no âmbito dos cursos de formação de professores, principalmente naqueles voltados para o Atendimento Educacional Especializado (AEE) e a 
Research, Society and Development, v. 10, n. 2, e5510212244, 2021

(CC BY 4.0) | ISSN 2525-3409 | DOI: http://dx.doi.org/10.33448/rsd-v10i2.12244

Educação Inclusiva, pois tornará mais visível essa problemática, e assim proporcionará, na formação de novos cursos, a inserção de estudos direcionados às pessoas disléxicas.

\section{Referências}

American Psychiatric Association (2014). Manual Diagnóstico e Estatístico de Transtornos Mentais: DSM 5. (5a ed.), Artmed.

Assunção, G. S. (2018). A dislexia e os desafios no processo de aprendizagem da língua portuguesa. Monografia (Licenciatura em Língua Portuguesa e Literaturas). 49 f. Santo Antônio de Jesus: Universidade do Estado da Bahia.

Carreira, F. K. do N. (2016). Reflexões sobre dislexia e o papel do professor (Trabalho Monográfico em Educação). Universidade Federal Fluminense-UFF.

Gardner, H. (1994). Estruturas da Mente: a teoria das inteligências múltiplas. ArtMed.

Maradei, A. P. P. C., Maia, G. S. A., Seabra, M. A. S. (2020). Dislexia: das dificuldades ao desenvolvimento de potencialidades In Seabra, M.A.B. (Org), Distúrbios e transtornos de aprendizagem: aspectos teóricos, metodológicos e educacionais (pp. 49-57) Curitiba/PR: Bagai.

Pereira, A. S., Shitsuka, D. M., Parreira, F. J., Shitsuka, R. (2018). Metodologia da Pesquisa Científica. UAB/NTE/UFSM. https://www.ufsm.br/app/uploads/sites/358/2019/02/Metodologia-da-Pesquisa-Cientifica_final.pdf.

Ramos, I. A. V., Seabra, M. A. B., \& Toledo, R. G. M. (2018). Resgatando o percurso da aprendizagem. In I.A.V. Ramos \& J.M.C. Rodrigues (Orgs), Teorizando a prática e praticando a teoria: expressões de docência (pp. 31-40): Editora do CCTA/UFPB.

Rubino, R. (2008). Sobre o conceito de dislexia e seus efeitos no discurso social. In.: Estilos da Clínica, Vol. XIII, nº $24,84-97$.

Santos, J. L. G., Erdmann, A. L., Meirelles, B. H. S., Lanzoni, G. M. M., Cunha, V. P., Ross, R. (2017). Integração entre dados quantitativos e qualitativos em uma pesquisa de métodos mistos. Texto Contexto Enferm; 26(3):e1590016.

Seabra, M. A. B. (2013). Diálogos com professoras sobre o Transtorno de Déficit de Atenção e Hiperatividade (TDAH). João Pessoa: Editora UFPB.

Seabra, M. A. B., Almeida, D. S., \& Félix, V. S. (2016). Espectro Autista Infantil: um olhar psipedagógico. In M. D. Palitot, M. A. B. Seabra, T. S. J. Pires \& H. M. L. Silva (Orgs.), Caminhos e Reflexões Psicopedagógicas e Interdisciplinares para Aprender a Aprender. 213-226, Idea.

Seabra, M. A. B., Santiago, S. M. S. (2020). Educação e Diversidade: exclusão e inclusão. In M.A.B. Seabra, E.S. Santos, E.S. \& S.S. Santos (Orgs), Transtornos e Distúrbios de Aprendizagem nos tempos de inclusão, 111-125. Editora do CCTA/UFPB. 